\title{
Anthropogenic and natural sources of ambient noise in the ocean
}

\author{
John A. Hildebrand* \\ Scripps Institution of Oceanography, University of California San Diego, La Jolla, California 92093-0205, USA
}

\begin{abstract}
Ocean ambient noise results from both anthropogenic and natural sources. Different noise sources are dominant in each of 3 frequency bands: low (10 to $500 \mathrm{~Hz}$ ), medium (500 Hz to $25 \mathrm{kHz}$ ) and high (>25 kHz). The low-frequency band is dominated by anthropogenic sources: primarily, commercial shipping and, secondarily, seismic exploration. Shipping and seismic sources contribute to ambient noise across ocean basins, since low-frequency sound experiences little attenuation, allowing for long-range propagation. Over the past few decades the shipping contribution to ambient noise has increased by as much as $12 \mathrm{~dB}$, coincident with a significant increase in the number and size of vessels comprising the world's commercial shipping fleet. During this time, oil exploration and construction activities along continental margins have moved into deeper water, and the long-range propagation of seismic signals has increased. Medium frequency sound cannot propagate over long ranges, owing to greater attenuation, and only local or regional (10s of $\mathrm{km}$ distant) sound sources contribute to the ambient noise field. Ambient noise in the mid-frequency band is primarily due to sea-surface agitation: breaking waves, spray, bubble formation and collapse, and rainfall. Various sonars (e.g. military and mapping), as well as small vessels, contribute anthropogenic noise at mid-frequencies. At high frequencies, acoustic attenuation becomes extreme so that all noise sources are confined to an area close to the receiver. Thermal noise, the result of Brownian motion of water molecules near the hydrophone, is the dominant noise source above about $60 \mathrm{kHz}$.
\end{abstract}

KEY WORDS: Acoustics $\cdot$ Ocean ambient noise $\cdot$ Shipping $\cdot$ Sonar $\cdot$ Seismic exploration $\cdot$ Wave action Resale or republication not permitted without written consent of the publishe

\section{INTRODUCTION}

Ambient sound is an important aspect of marine habitat (Richardson et al. 1995, Halpern et al. 2008). Sound is an extremely efficient way to propagate energy through the ocean, and marine organisms have evolved to exploit this property. Fish utilize sound for navigation and selection of habitat, mating, and communication (Bass \& McKibben 2003, Simpson et al. 2005). Marine mammals use sound as a primary means for underwater communication and sensing (Wartzok \& Ketten 1999). Toothed whales have developed sophisticated echolocation systems to sense and track the presence of prey (Au 1993). Baleen whales have developed long-range acoustic communication systems to facilitate mating and social interaction (EddsWalton 1997). Marine organisms may be expected to choose their locations and modify their behavior based, in part, on natural and anthropogenic background noise. Knowledge about the characteristics of ocean noise and its distribution relative to the location and movements of marine organisms is important for understanding the potential impacts of anthropogenic sound.

Ambient noise in the ocean is the sound field against which signals must be detected. In the ambient noise field, it is often difficult to ascribe a particular sound to a localized source. The character of ambient noise results both from the characteristics of the multitude of contributing sound sources and the ability of sound to propagate efficiently from one location to another.

Noise in the ocean is the result of both natural and anthropogenic sources. Natural sources of noise include processes such as earthquakes, wind-driven 
waves, rainfall, bio-acoustic sound generation, and thermal agitation of the seawater. Anthropogenic noise is generated by a variety of activities, including commercial shipping; oil and gas exploration, development, and production (e.g. air-guns, ships, oil drilling); naval operations (e.g. military sonars, communications, and explosions); fishing (e.g. commercial/civilian sonars, acoustic deterrent, and harassment devices); research (e.g. air-guns, sonars, telemetry, communication, and navigation); and other activities such as construction, icebreaking, and recreational boating. Sources of anthropogenic noise are becoming both more pervasive and more powerful, increasing oceanic background noise levels as well as peak sound intensity levels. Many sources of noise are located along well-traveled paths in the sea and encompass coastal and continental shelf waters, areas that represent important marine habitat.

\section{ACOUSTIC UNITS AND STANDARDS}

The decibel is a logarithmic unit used to describe the strength of acoustic fields, in terms of a base 10 scale. Decibels, originally defined by electrical engineers, are a shorthand method to describe power and voltage ratios. In acoustics, the corresponding units are acoustic intensity (power per unit area) and sound pressure level (SPL, force per unit area), and in decibels these are defined as follows:

$$
\begin{gathered}
\text { Intensity level (in } \mathrm{dB})=10 \log _{10}\left(I / I_{\text {ref }}\right) \\
\text { SPL (in } \mathrm{dB})=10 \log _{10}\left(\mathrm{p} / \mathrm{p}_{\mathrm{ref}}\right)^{2}=20 \log _{10}\left(\mathrm{p} / \mathrm{p}_{\text {ref }}\right)
\end{gathered}
$$

where for plane and spherical acoustic waves, the acoustic intensity $I$ and pressure $\mathrm{p}$ are related by the characteristic impedance $Z$ of the medium:

$$
I=\mathrm{p}^{2} / Z \quad\left(\text { in } \mathrm{W} \mathrm{m}^{-2}\right)
$$

It is understood that the expression for decibels using pressure originates from taking the reference as the intensity of a plane wave or spherical wave. The modern standard of pressure is $10^{-6} \mathrm{~N} \mathrm{~m}^{-2}$, called a microPascal $(\mu \mathrm{Pa})$. In the past, a commonly used pressure unit was the dyne $\mathrm{cm}^{-2}(1 \mu \mathrm{bar})$, and the conversion factor to microPascal is $100 \mathrm{~dB}$. For omni-directional sources the acoustic power $(P)$ is given by the solid angle $(A)$ emitted by the source (for an omnidirectional source this is $4 \pi$, the area of a sphere of $1 \mathrm{~m}$ radius) multiplied by the acoustic intensity $(I)$.

$$
P=A \times I \quad\left(\text { in } \mathrm{W}=\mathrm{J} \mathrm{s}^{-1}\right)
$$

The energy per source transmission or ping $\left(E_{\text {ping }}\right)$ is given by the acoustic power, multiplied by the duration, $T_{\text {ping, }}$ of the transmission:

$$
E_{\text {ping }}=P \times T_{\text {ping }} \quad(\text { in } \mathrm{J})
$$

For continuous (or quasi-continuous) signals, the standard procedure is to measure pressure as the rootmean-square (RMS) of the signal. Unless stated otherwise, underwater acoustic pressure measurements are understood to be in RMS. However, this presents problems for short-duration signals (such as seismic airguns), where the duration of the signal being measured is an important parameter (Madsen 2005). In these cases it may be more appropriate to measure pressure as the peak-to-peak signal, rather than as RMS. For continuous signals, the RMS signal level is approximately $9 \mathrm{~dB}$ less than the peak-to-peak level. For pulsed signals, even greater differences are obtained, depending on the time window used for RMS analysis.

The bandwidth of the acoustic signal is also an important component of how the signal is described. For noise signals, the standard is to describe broadband energy in $1 \mathrm{~Hz}$ wide frequency analysis bins, and these are called the spectrum level. For source signals, however, the standard is to describe the energy across a band encompassing the entire signal (for instance from the breadth of the $-3 \mathrm{~dB}$ points on either side of the peak frequency), and this is called the band level.

Signals from a particular source, when referenced to a fixed distance (typically taken as $1 \mathrm{~m}$ ), are called the source level (SL). When measurements are made at greater or lesser distances, they are called the received level, and are then adjusted to the reference distance for comparison.

Sources of natural and anthropogenic sound differ with respect to their physical characteristics. These sound sources may be described using their sound pressure level, spectrum level, rise time, duty cycle, and repetition rate, all of which are characteristics that may be important to adequately describe a sound source.

The sound field observed from a particular source depends on the characteristics of the source and on the ocean environment. Near the source, the sound pressure level is determined largely by the source characteristics. Propagating away from the source, sound waves spread out and attenuate at rates that vary according to the specific conditions. As distance from the source increases, environmental factors are increasingly important in defining the sound field. Sound speed varies with temperature (among other variables), and the ocean's temperature structure will affect the propagation paths that sound will follow, leading to interaction with the ocean bottom and surface and, ultimately, determining the distance at which the sound will contribute to the ambient noise field. 


\section{ANTHROPOGENIC NOISE SOURCES}

Anthropogenic noise in the ocean comes from a variety of sources, some of which make sound intentionally, and others produce sound as an unintended byproduct of other activities. Among those sources that produce sound intentionally are explosions, seismic exploration, sonars, and acoustic deterrent devices. Sources where sound is an unintended by-product include shipping and industrial activities. The characteristics of typical ocean anthropogenic noise sources are given in Table 1.

\section{Explosives}

Chemical explosives are used for several purposes underwater including seismic surveying, removal of structures, ship shock trials, military mines, bombs, torpedoes and shells, and small charges used to deter marine mammals (seal bombs). Explosions create a pressure impulse with a sharp rise time that is relatively broadband in frequency, including low-frequency energy. Explosions generally have high source levels. The spectral and amplitude characteristics of explosions vary with the weight of the charge and the depth of the detonation. For a chemical charge, the source level of the initial shock wave for a large component of the energy is given by

$$
\left.\mathrm{SL}=269 \mathrm{~dB}+7.53 \log _{10}(w) \text { (in dB re } 1 \mu \mathrm{Pa} @ 1 \mathrm{~m}\right)
$$

where $w$ is the charge weight equivalent in pounds of TNT (Urick 1975, NRC 2003). For instance, 10000 lbs (4536 kg) of TNT equivalent of explosive used for a ship shock trial (NMFS 2001) produces an initial shock wave with a SL of $299 \mathrm{~dB}$ re $1 \mu \mathrm{Pa} @ 1 \mathrm{~m}$, and a peak energy in the frequency band from 0.5 to $50 \mathrm{~Hz}$ (Table 1). The additional energy from the bubble pulse oscillations will contribute $\sim 5 \mathrm{~dB}$ to the source level, yielding a total SL of $304 \mathrm{~dB}$ re $1 \mu \mathrm{Pa} @ 1 \mathrm{~m}$. Likewise, a MK-46 torpedo detonation with $98 \mathrm{lbs}(44 \mathrm{~kg}$ ) (of TNT equivalent) explosive would produce a total SL of $289 \mathrm{~dB}$ re $1 \mu \mathrm{Pa} @ 1 \mathrm{~m}$ (including the initial shock and bubble pulse), with an almost constant frequency content between 10 and $200 \mathrm{~Hz}$ (Table 1).

The sounds from an explosion propagate equally in all directions. They typically are detectable on regional scales, although in some cases a single shot has been detected over several ocean basins (Munk et al. 1988). A large number (300 to $4000 \mathrm{mo}^{-1}$ ) of underwater explosions were reported in the North Pacific during the 1960s (Spiess et al. 1968). These shots must have served a variety of purposes, including oil exploration. Explosions have been now replaced by air-gun arrays for most oil exploration work. Explosions continue to be used in the construction and removal of undersea structures, and during the practice of blast fishing and coral mining.

Seal bombs are small explosive charges that are detonated by fishermen to deter seals and sea lions from competing for fish. Seal bombs also have been used to deter pinnipeds from occupying recreational boat and dock areas, inhabiting public swimming areas, and foraging on endangered salmon species at fish ladders and dams. Seal bombs contain $\sim 2.3 \mathrm{~g}$ of explosive charge mixture in a sealed cardboard tube, fitted with a waterproof fuse. They are weighted to sink below the surface of the water before detonation (Myrick et al.

Table 1. Typical sources of anthropogenic noise. Omni: omnidirectional; CW: continous wave; V: vertical; $\mathrm{H}:$ horizontal; 10000 lb = $4536 \mathrm{~kg} ; 98 \mathrm{lb}=44 \mathrm{~kg}$

\begin{tabular}{|c|c|c|c|c|c|c|}
\hline Sound source & $\begin{array}{c}\text { Source level } \\
(\mathrm{dB} \text { re } 1 \mu \mathrm{Pa} @ 1 \mathrm{~m})\end{array}$ & $\begin{array}{l}\text { Power } \\
\text { (W) }\end{array}$ & $\begin{array}{l}\text { Total energy } \\
\text { per pulse }(\mathrm{J})\end{array}$ & $\begin{array}{c}\text { Bandwidth } \\
\Delta=10 \mathrm{~dB}(\mathrm{~Hz})\end{array}$ & $\begin{array}{l}\text { Source } \\
\text { direction }\end{array}$ & $\begin{array}{c}\text { Pulse } \\
\text { duration (s) }\end{array}$ \\
\hline Ship shock trial (10000 lb explosive) & 304 & $0.021 \times 10^{15}$ & $0.042 \times 10^{15}$ & $0.5-50$ & Omni & 2 \\
\hline Torpedo MK-46 (98 lb explosive) & 289 & $0.66 \times 10^{12}$ & $0.066 \times 10^{12}$ & $10-200$ & Omni & 0.1 \\
\hline Air-gun array & 260 & $0.21 \times 10^{9}$ & $6.2 \times 10^{6}$ & $5-300$ & $60 \times 180^{\circ} \mathrm{V}$ & 0.03 \\
\hline US Navy 53C ASW sonar & 235 & $0.77 \times 10^{6}$ & $1.5 \times 10^{6}$ & $2000-8000$ & $40 \times 360^{\circ} \mathrm{H}$ & 2 \\
\hline SURTASS LFA sonar & 235 & $0.59 \times 10^{6}$ & $0.029 \times 10^{9}$ & $100-500$ & $30 \times 360^{\circ} \mathrm{H}$ & $6-100$ \\
\hline Pile-driving $1000 \mathrm{~kJ}$ hammer & 237 & $0.46 \times 10^{6}$ & $0.023 \times 10^{6}$ & $100-1000$ & $15 \times 360^{\circ} \mathrm{H}$ & 0.05 \\
\hline Multibeam sonar deep-water EM 122 & 245 & $0.077 \times 10^{6}$ & 760 & $11500-12500$ & $1.0 \times 120^{\circ} \mathrm{V}$ & 0.01 \\
\hline Seal bombs ( $2.3 \mathrm{~g}$ charge) & 205 & $2.6 \times 10^{3}$ & 79 & $15-100$ & Omni & 0.03 \\
\hline Multibeam sonar shallow EM 710 & 232 & $2.2 \times 10^{3}$ & 4.5 & $70000-100000$ & $0.5 \times 140^{\circ} \mathrm{V}$ & 0.002 \\
\hline Sub-bottom profiler SBP 120 & 230 & $2.1 \times 10^{3}$ & 210 & $3000-7000$ & $3 \times 35^{\circ} \mathrm{V}$ & 0.1 \\
\hline Acoustic harassment device & 205 & $1.3 \times 10^{3}$ & 330 & $8000-30000$ & $90 \times 360^{\circ}$ & $0.15-0.5$ \\
\hline Cargo vessel (173 m length, 16 knots) & 192 & 66 & - & $40-100$ & $80 \times 180^{\circ}$ & $\mathrm{CW}$ \\
\hline Acoustic telemetry SIMRAD HTL 300 & 190 & 42 & - & $25000-26500$ & $90 \times 360^{\circ}$ & $\mathrm{CW}$ \\
\hline Small boat outboard engine ( 20 knots) & 160 & $42 \times 10^{-3}$ & - & $1000-5000$ & $80 \times 180^{\circ}$ & $\mathrm{CW}$ \\
\hline Acoustic deterrent device & 150 & $4.2 \times 10^{-3}$ & $1.4 \times 10^{-3}$ & $5000-160000$ & $90 \times 360^{\circ}$ & $0.2-0.3$ \\
\hline Operating windmill turbine & 151 & $2.6 \times 10^{-3}$ & - & $60-300$ & $15 \times 360^{\circ} \mathrm{H}$ & $\mathrm{CW}$ \\
\hline
\end{tabular}


1990). The time delay between when the fuse is lit and when the unit enters the water allows regulation of depth at detonation. Measured seal bomb SLs are $205 \mathrm{~dB}$ re $1 \mu \mathrm{Pa} @ 1 \mathrm{~m}$ (Table 1), with a duration of $30 \mathrm{~ms}$ (Awbrey \& Thomas 1987). These values are less than the value predicted for $2.3 \mathrm{~g}$ of explosives by Eq. (6) (251 dB re $1 \mu \mathrm{Pa} @ 1 \mathrm{~m}$ ) owing to the shallow depth of their detonation and subsequently low confining pressure.

\section{Seismic exploration}

The sound-producing elements used in oil exploration are air-gun arrays, which are towed from marine vessels (Dragoset 1984, 2000). Air-guns release a volume of air under high pressure (about 2000 psi), creating a sound wave from the expansion and contraction of the released air bubble. To yield high acoustic intensities, multiple air-guns (typically 12 to 48) are fired with precise timing to produce a coherent pulse of sound. The sound pressure level output from an airgun array is proportional to its operating pressure, the number of air-guns, and the cube root of the total gun volume. For consistency with the underwater acoustic literature, air-gun-array source levels are calculated as an equivalent source concentrated in a $1 \mathrm{~m}$ radius volume (Table 1), yielding source-levels of up to $260 \mathrm{~dB}$ rms re $1 \mu \mathrm{Pa} @ 1 \mathrm{~m}$ output pressure (Turner et al. 2006). This effective source level predicts pressures in the farfield of the array, but, in the near-field, the maximum pressure levels encountered are limited to between 220 and $230 \mathrm{~dB}$ peak re $1 \mu \mathrm{Pa}$. The peak spectral levels for industry arrays are in the 5 to $300 \mathrm{~Hz}$ range, although energy up to $3 \mathrm{kHz}$ has been reported from the use of air-guns during controlled exposure experiments with sperm whales (Madsen et al. 2006). Airguns are towed at speeds of about 5 knots and are typically fired about every 10 to $20 \mathrm{~s}$. There are $>90$ seismic vessels available worldwide (Schmidt 2004), and about $20 \%$ of them are conducting field operations at a given time (Tolstoy et al. 2004).

\section{Sonar}

Low-frequency active (LFA) sonars are used for broadscale military surveillance; they are designed to provide the sound source over scales of 100s of kilometers for other passive listening platforms to detect submarines. Specialized support ships are used to deploy LFA sonars, which consist of arrays of source elements suspended vertically below the ship. The United States Navy's Surveillance Towed Array Sensor System (SURTASS) LFA sonar uses an array of up to 18 projectors operating in the frequency range from 100 to $500 \mathrm{~Hz}$, with a $215 \mathrm{~dB}$ re 1 $\mu \mathrm{Pa} @ 1 \mathrm{~m}$ source level for each projector (Anonymous 2007). These systems are designed to project beams of energy in a horizontal direction, with a vertical beam width that can be steered above or below the horizontal. The effective source level of an LFA array (Table 1) can be $235 \mathrm{~dB}$ re $1 \mu \mathrm{Pa} @ 1 \mathrm{~m}$ or higher (Evans \& England 2001). The signal includes both constant-frequency (CF) and frequency-modulated (FM) components with bandwidths of approximately $30 \mathrm{~Hz}$. A ping sequence can last 6 to $100 \mathrm{~s}$, with a time between pings of 6 to 15 min and a typical duty cycle of $10 \%$. Signal transmissions are emitted in patterned sequences that may last for days or weeks. There are currently 2 LFA source ships, with a proposed expansion to 4 source ships by 2011 (DoN 2009).

Sonars used for detecting submarines at moderate range $(<10 \mathrm{~km})$ use mid-frequencies at high source levels. They are incorporated into the hulls of naval surface vessels such as destroyers, cruisers, and frigates. There are about 300 mid-frequency sonars in active service in the world's navies (Watts 2003). The AN/SQS-53C (Table 1) is a surface ship mid-frequency sonar in use by the United States Navy, which generates FM pulses of 1 to $2 \mathrm{~s}$ duration in the 1 to $5 \mathrm{kHz}$ band, at source levels of $235 \mathrm{~dB}$ re $1 \mu \mathrm{Pa} @ 1 \mathrm{~m}$ or higher. This sonar has a nominal $40^{\circ}$ vertical beam width, directed $3^{\circ}$ down from the horizontal direction, and can broadcast over $360^{\circ}$ horizontally (with some baffling to the rear of the ship by the hull and the wake).

Civilian and commercial sonars are used for detection, localization, and classification of various underwater targets (e.g. the ocean floor, plankton, fish, divers). These sonars generally produce sound at lower source levels than do military sonars, but may be more ubiquitous owing to the large number of commercial vessels that are equipped with sonar. Seafloor mapping and echosounding sonars transmit sound pulses directed towards the ocean bottom. The timing of the return echo indicates the water depth. A significant percentage of both large and small vessels is equipped with some form of commercial sonar for water depth sounding (NRC 2003), typically these echosounders are operated much of the time in which a ship is at sea, as an aid for navigation. Mapping sonars are similarly used to collect data on seafloor bathymetry; they may be single beam (1 depth point collected per ping) or multibeam (multiple depth points collected). A multibeam sonar uses an array of many active transducers. The transducer array produces a swath of acoustic energy, directed across the track of the vessel. By combining the returning echos to calculate their angle of arrival, it is possible to determine the depth for a swath of points beneath the vessel, greatly speeding the coverage for seafloor mapping. The frequency of seafloor 
mapping sonars varies from mid-frequency $(12 \mathrm{kHz})$ for deep-water systems (Table 1: EM122) to high-frequency (70 to $100 \mathrm{kHz}$ ) for shallow water mapping systems (Table 1: EM170). Multibeam sonars are operated at high source levels (245 dB re $1 \mu \mathrm{Pa} @ 1 \mathrm{~m}$ for the EM122; Table 1), but have highly directional beams $\left(1 \times 120^{\circ}\right.$ for EM122). Sub-bottom profilers image seafloor sediment layers and buried objects (Table 1: SPB120). These sonars produce a mid-frequency (3 to $7 \mathrm{kHz}$ ) and high source level (230 dB re $1 \mu \mathrm{Pa} @ 1 \mathrm{~m})$ pulse, so that deep penetration into the sediments is obtained.

Hydroacoustic sonars are used to detect the presence of living organisms and particles in oceans, lakes, and rivers (Simmonds \& MacLennan 2005). By transmitting sound at mid- and high frequencies (20 to $1000 \mathrm{kHz}$ ), hydroacoustic sonars can detect individual objects or aggregates, such as schools of fish, in the water column. The abundance of scattering objects is derived from the strength of the sonar echoes. Data from multiple sonar frequencies are used to infer scattering from different fish species, or various zooplankton size groups, since the amount of scattered acoustic energy will vary with object size and acoustic wavelength. Information on the sizes of scattering objects present and their distribution patterns (e.g. depth, diel, and seasonal cycles) is obtained. Hydroacoustic surveys traditionally are conducted from boats to evaluate fish or zooplankton biomass and spatial distributions. Fixed sites, such as buoys, use stationary transducers to monitor passing biomass.

Scanning sonars and synthetic aperture sonars are used for harbor defense, and underwater search and recovery. The goal of these sonars is to provide a reflective map of the seafloor or targets in the water column. With mechanically scanned sonars an acoustic ping is transmitted, and the system waits to receive the echoed returns. The waiting time is directly proportional to the desired range. After the transmit/receive interval is completed, a motor steps the transducer to a new azimuth angle, and the process is repeated. Frequencies between 85 and $100 \mathrm{kHz}$ are optimum for diver/swimmer detection. Synthetic aperture and sidescan sonars are operated from towed vehicles. The reflective profiles from each ping are concatenated to form an image of the seafloor, as the sonar is translated along with the towed vehicle. High frequencies (e.g. $100 \mathrm{kHz}$ ) are used to obtain high resolution of seafloor features.

\section{Acoustic deterrent and harassment devices}

Acoustic sources at mid- to high frequencies are used as acoustic deterrent devices (ADD) and acoustic harassment devices (AHD) to modify marine mammal behavior. The goal of these devices is to keep marine mammals away from fishing gear or aquaculture facilities (Pepper et al. 2004). ADDs or pingers typically produce low sound levels (150 dB re $1 \mu \mathrm{Pa} @ 1 \mathrm{~m}$; Table 1) and are used to discourage marine mammals from approaching fishing gear. AHDs emit tone pulses or pulsed frequency sweeps at high source levels $(205 \mathrm{~dB}$ re $1 \mu \mathrm{Pa} @ 1 \mathrm{~m}$; Table 1). AHDs are intended to produce aversive responses at local ranges and are used to keep seals and sea lions away from aquaculture facilities or fishing equipment. Both pingers and AHDs have frequencies in the 5 to $160 \mathrm{kHz}$ band, and generate pulses lasting from 2 to $2000 \mathrm{~ms}$. To reduce habituation, a single device may transmit with a variety of waveforms and time intervals.

\section{Ships}

Commercial ships are a ubiquitous feature of the world's oceans. Analysis of noise from ships revealed that their propulsion systems are a dominant source of radiated underwater noise at frequencies $<200 \mathrm{~Hz}$ (Ross 1976). Cavitation at the propeller blade tips was found to be a significant noise mechanism across all frequencies, though the higher frequencies do not propagate far. Cavitation occurs when the local static pressure drops below a critical value; it can be characterized as boiling of the seawater, brought about by static pressure decrease. Cavitation noise includes both broadband noise due to bubble collapse, and tonal components that are related to blade passage frequency and higher harmonics. Additional sources of ship noise include rotational machinery that produces tones, and reciprocating machines that produce sharp pulses at a constant repetition rate, resulting in multiple harmonics of the repetition frequency. From the nature of the spectra, it is possible to deduce information about the nature of the shipboard noise source.

Individual vessels produce unique acoustic signatures, although these signatures may change with ship speed, vessel load, and activities that may be taking place on the vessel. Sharp tonal peaks produced by rotating and reciprocating machinery, such as diesel engines, diesel generators, pumps, fans, blowers, hydraulic power plants, and other auxiliaries, are often seen in these acoustic signatures. Hydrodynamic flow over the ship's hull and hull appendages is an important broadband sound-generating mechanism, especially with increased ship speed. Peak spectral levels for individual commercial ships are in the frequency band of 10 to $50 \mathrm{~Hz}$ and range from $195 \mathrm{~dB}$ re $\mu \mathrm{Pa}^{2} / \mathrm{Hz}$ @ $1 \mathrm{~m}$ for fast-moving (>20 knots) supertankers to 
$140 \mathrm{~dB}$ re $\mu \mathrm{Pa}^{2} / \mathrm{Hz} @ 1 \mathrm{~m}$ for small fishing vessels (NRC 2003).

Small boats with outboard or inboard engines produce sound that is generally highest in the mid-frequency ( 1 to $5 \mathrm{kHz}$ ) range and at moderate (150 to $180 \mathrm{~dB}$ re $1 \mu \mathrm{Pa} @ 1 \mathrm{~m}$ ) source levels (Erbe 2002, Kipple \& Gabriele 2003, 2004). For instance, small craft with outboard motors (14 to 18 feet [4.3 to $5.5 \mathrm{~m}$ ] in length with 25 to 40 horsepower [19 to $30 \mathrm{~kW}$ ] outboard motors, and operated at a speed of from 10 to 20 knots) had maximum source levels (one-third octave band) at $160 \mathrm{~dB}$ re $1 \mu \mathrm{Pa} @ 1 \mathrm{~m}$, with peak energy at $5 \mathrm{kHz}$ (Kipple \& Gabriele 2003). On average, noise levels were found to be higher for the larger vessels, and increased vessel speeds resulted in higher noise levels.

\section{Industrial activities}

The noise from stationary industrial activities, such as oil drilling, construction pile driving, and offshore wind farms, typically have their highest energy at low frequencies (20 to $1000 \mathrm{~Hz}$ ) (Greene 1987). Offshore drilling is done from platforms, drilling-ships, or artificial islands and can produce nearly continuous noise at moderate source levels. Drilling from fixed platforms and artificial islands produces predominantly low to mid-frequency noise $(700$ to $1400 \mathrm{~Hz})$ at maximum source levels of 184 dB re 1 $\mu \mathrm{Pa} @ 1 \mathrm{~m}$ (Blackwell et al. 2004). Sound levels from drilling-ships are generally higher than from platforms or islands, with low-frequency tones and broadband signals in the low and mid-frequency bands. Drilling can be done from dynamically positioned drilling-ships, using thrusters to maintain their position; these operations may generate higher levels of sound than drilling from fixed platforms.

Pile driving produces noise at low frequencies and high source levels. The propagation of pile driving noise away from the impact site varies according to the ocean bottom type. The sounds from pile driving enter the water column directly and also through the ocean bottom. A study of pile driving noise in the San Francisco Bay (Caltrans 2001) involved driving 3 steel pipe piles using 2 types of hydraulic hammers, 1 with a maximum energy rating of $500 \mathrm{~kJ}$ and 1 with a maximum rating of $1700 \mathrm{~kJ}$. At $100 \mathrm{~m}$ range, received levels of $196 \mathrm{~dB}$ re $1 \mu \mathrm{Pa}$ were observed using a $918 \mathrm{~kJ}$ hammer. The relation between the calculated source level at $1 \mathrm{~m}$ and hammer energy was found to be:

$$
\mathrm{SL}=205.9+10.2 \log (H)(\text { in } \mathrm{dB} \text { rms re } 1 \mu \mathrm{Pa} @ 1 \mathrm{~m})
$$

where $H$ is the hammer energy in kilojoules. Each pile driving impulse was from 30 to $50 \mathrm{~ms}$ in duration, with repetition every 2 to $4 \mathrm{~s}$. These signals were at low frequencies (100 to $1000 \mathrm{~Hz}$ ).
Offshore wind farms create low-frequency noise at high source levels during their construction (e.g. pile driving), but at moderate source levels during their operation. The highest source level reported for the tonal noise component during operation of a windmill is $151 \mathrm{~dB}$ re $1 \mu \mathrm{Pa} @ 1 \mathrm{~m}$, for a wind speed of $13 \mathrm{~m} \mathrm{~s}^{-1}$, and at a frequency of $180 \mathrm{~Hz}$ (Wahlberg \& Westerberg 2005). The broadband low-frequency (10 to $1000 \mathrm{~Hz}$ ) source levels reported for 4 different wind farms were 100 to $120 \mathrm{~dB}$ re $1 \mu \mathrm{Pa} @ 1 \mathrm{~m}$.

Acoustic telemetry is used for underwater communications, remote vehicle command and control, diver communications, underwater monitoring and data logging, trawl net monitoring and other applications requiring underwater wireless communications. For seafloor monitoring, acoustic modems send data using modulated acoustic signals between seafloor instruments and surface buoys. Long-range systems operate over distances of up to $10 \mathrm{~km}$ using frequencies of 7 to $45 \mathrm{kHz}$, at source levels of up to $190 \mathrm{~dB}$ re $1 \mu \mathrm{Pa} @ 1 \mathrm{~m}$ (Table 1: HTL 300). Acoustic navigation is conducted with underwater transponders, which are used to establish a navigation baseline for underwater vehicles and to provide precise underwater positioning.

The representative list of anthropogenic sound sources in Table 1 is ordered according to their acoustic power output. Acoustic power is related to sound pressure level, with the additional consideration of source directionality. For pulsed sources, the total energy per ping is calculated from the acoustic power and the pulse duration. It is generally thought that total energy is more important than sound pressure level or acoustic power for predicting the potential for the source to inflict physical damage or injury owing to a short-term exposure (Christian \& Gaspin 1974). For continuous sources, such as ships, it is not possible to calculate total energy, unless the details of how long the source will be within range of the receiver is known. However, it is clear that continuous sources have a significant potential to contribute to ambient noise. An attempt to estimate the contribution of anthropogenic noise sources to the global ambient noise budget, accounting for the number and duty cycle for source usage, is presented in Hildebrand (2005).

\section{AMBIENT NOISE SPECTRA}

For purposes of understanding the sources and characteristics of ocean ambient noise, it can be divided into 3 frequency bands: low (10 to $500 \mathrm{~Hz}$ ), medium ( $500 \mathrm{~Hz}$ to $25 \mathrm{kHz}$ ) and high (> $25 \mathrm{kHz}$ ). A different set of noise sources dominates each band, and there are different capabilities for the noise to propagate away 
from the source. In general, low-frequency sources have significant potential for long-range propagation, as they experience little attenuation. The low-frequency ambient noise field, therefore, can be a summation of noise across an entire ocean basin. In contrast, medium frequencies have a limited potential for propagation, owing to their greater attenuation, and, therefore, only local or regional (within a few 10s of kilometers of the receiver) sources contribute to the ambient noise field. At high frequencies, acoustic attenuation becomes extreme (e.g. $30 \mathrm{~dB} \mathrm{~km}^{-1}$ at $100 \mathrm{kHz}$ ) so that all noise sources are confined to an area within a few kilometers of the receiver.

A generalized deep-water ocean ambient noise spectrum is presented in Fig. 1. This graph follows the style of Wenz (1962), but it has been modified to reflect higher levels of low-frequency ambient noise than levels common in the 1960s, owing to increased anthropogenic activity (McDonald et al. 2006) and an improved understanding of low-frequency noise levels in the absence of anthropogenic sources (Kewley et al. 1990, Cato \& McCauley 2002).

For most of the world's oceans, shipping and seismic noise dominate the low-frequency portion of the spectrum. Local wind noise dominates the mid-frequency portion of the spectrum, and, therefore, a series of curves are presented for varying sea states. Fig. 1 follows Knudsen et al. (1948) for the contribution of local wind noise, but within a narrower band of frequencies than originally proposed, again reflecting the presence of higher levels of anthropogenic noise at low frequencies, which has shifted the boundary between noise

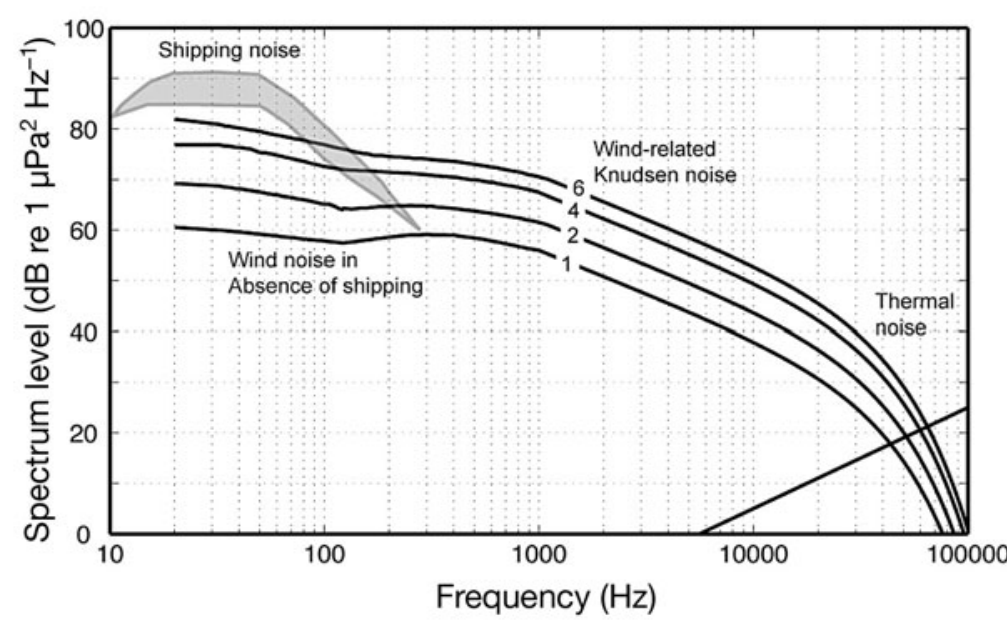

Fig. 1. Generalized ocean ambient noise spectral levels for a deep-water site with the receiver located at $1000 \mathrm{~m}$ depth. Four different noise mechanisms are denoted in the plot: thermal noise (Mellen 1952); windrelated noise (Knudsen et al. 1948), which is a function of sea state (numbered curves); wind noise at low frequency observed in the absence of shipping (Cato \& McCauley 2002); and modern shipping noise (greyshading) (McDonald et al. 2006) dominated by shipping and by wind. At high frequencies and at depth, wind noise falls off faster with increasing frequency than expected, owing to attenuation of surface noise sources. This decrease in wind noise sets the boundary between wind noise and thermal noise, which dominates at high frequencies. Thermal noise is a result of Brownian motion of water molecules near the hydrophone, following the predictions of Mellen (1952).

The highest levels of ocean ambient noise within the band of interest (10 Hz to $100 \mathrm{kHz}$ ) are seen at low frequencies. The frequency band from 10 to $500 \mathrm{~Hz}$ has a broad maximum around 10 to $80 \mathrm{~Hz}$, with a steep negative slope above $80 \mathrm{~Hz}$. There is strong evidence that this band is dominated by anthropogenic noise sources, primarily distant shipping traffic (Wenz 1972). There is also evidence for an increasing contribution from seismic profiling (Nieukirk et al. 2004) and to a lesser extent LFA sonar (Johnson 2002). Earthquakes contribute to low-frequency noise, primarily with a water-propagating component called T-phase (Butler 2006). Long-period ocean-surface waves (infragravity waves) dominate ambient noise at frequencies of $10 \mathrm{~Hz}$ and below (Webb 1998).

The shipping noise component of low-frequency ambient noise is a result of the ship traffic within an entire ocean basin, occurring even when no ships are seen near the receiver. It is only possible to discern the wind noise contribution to low-frequency noise by making measurements in areas remote from shipping, such as in the South Pacific (Cato 1976) or in areas bathymetrically shielded from propagation of distant shipping noise (McDonald et al. 2008). Owing to the distant origin of shipping and seismic noise, it preferentially arrives at near horizontal angles $\left( \pm 15^{\circ}\right)$, using refracted paths for long-range propagation. The lack of significant acoustic attenuation at low frequencies results in basin-wide summation of these noise sources.

The primary noise source in the mid-frequency band ( $500 \mathrm{~Hz}$ to $25 \mathrm{kHz}$ ) is sea-surface agitation, and noise measurements here correlate well with local wind speed and sea-state measurements (Knudsen et al. 1948). For midfrequencies, ambient noise typically has a peak around 300 to $500 \mathrm{~Hz}$ and decreases by -17 dB for each power of ten increase in frequency. The processes that contribute to noise in this frequency band are breaking white caps, spray, bubble formation and collapse, and rainfall. These noise sources tend to be local to the measurement site, and, therefore, ambient noise in the mid-frequency band is more intense in a vertical than in a horizontal 
direction. The contribution of surface agitation is diminished when the receiver is located at depth, owing to attenuation of high-frequency energy (Short 2005). Various sonars also contribute noise at mid-frequencies, such as military and mapping sonars. However, the range of their influence is limited to a few $10 \mathrm{~s}$ of kilometers.

Thermal noise associated with molecular agitation local to the hydrophone is the mechanism that sets ocean ambient noise at high frequencies. Predictions of the thermal noise spectrum, derived from classical statistical mechanics, suggest increasing noise with frequency with a positive slope of $6 \mathrm{~dB}$ octave $\mathrm{c}^{-1}$. Thermal agitation dominates ambient noise measurements in the band above $50 \mathrm{kHz}$ (Mellen 1952). Owing to its generation at or near the hydrophone, thermal noise is spatially isotropic.

Ambient noise can be modeled by combining what is known about source spectra and source distributions along with acoustic propagation. Source spectra explain many features of the ambient noise, including its spectral shape, geographical variations, and the observed long-term trends at low frequencies. Propagation effects explain the dominance of different sources within different frequency bands, the depth dependence of noise, and the characteristics of shallow water noise spectra.

The spectral shape of ambient noise follows that of the dominant noise sources. For instance, the noise of commercial ships is primarily at low frequencies, dominated by noise from the ship's propulsion system, including broadband noise from propeller cavitation and low-frequency, narrow-band tonal signals from rotating machinery. The radiated acoustic noise from a ship measured at close range, however, covers a frequency range that is much greater than that detected as ambient noise due to distant shipping (Kipple \& Kollars 2004), since propagation removes the highfrequency portion of the spectrum.

Ocean environmental factors that are important for acoustic propagation and thereby influence ambient noise are (1) the sound speed structure of the ocean for long-range propagation, (2) the acoustic attenuation of seawater, (3) the water depth (especially for shallow water propagation), and (4) the geo-acoustic properties of the ocean bottom (Kuperman 1988). For example, comparable noise sources may produce higher noise levels when radiating into a sound channel, owing to favorable propagation. Low-frequency sound may propagate greater distances within a sound channel, owing to refracted sound propagation paths. In contrast, paths that involve multiple bottom reflections experience greater attenuation and, thereby, do not contribute to the basin-wide ambient noise field.

\section{LOW-FREQUENCY AMBIENT NOISE}

Explosions, such as military ship-shock trials and torpedoes, are the sound sources that produce the highest overall SPLs, acoustic power, and total energy per pulse (Table 1). Detonation of explosive sources, however, may be rare events, and so they may have limited impact on global ambient noise levels. Air-gun arrays, likewise, have high SPLs, but their widespread usage may provide greater potential for contribution to the ambient sound field. As oil exploration has moved into deeper water during the past few decades, the potential for long-range propagation of seismic signals has increased. In shallow water settings, pile driving may result in high noise levels, but the potential for longrange propagation of these sources is limited. Military SURTASS-LFA sonars have high source levels and their long pulse lengths increase their total energy levels. In addition, these sonars are designed for longrange propagation. Commercial vessels are arguably the most ubiquitous low-frequency noise source, and their impact on ambient noise is basin wide, although their impact on ambient noise levels is especially concentrated near major ports and along the most heavily traveled shipping lanes.

\section{Shipping noise and distribution}

Commercial shipping is a significant component of ocean ambient noise at low frequency. It was discovered soon after World War II that there is virtually no correlation between local sea state and ambient noise below about $200 \mathrm{~Hz}$ for most locations. Analysis of commercial shipping revealed that distant vessels could account for the measured levels of low-frequency ambient noise.

In the absence of close sources, ambient noise at low frequency is due to many distant ships scattered throughout the ocean basin. An example of a shipping distribution model for the Pacific and Atlantic Oceans is presented in Fig. 2. The historical temporal shipping (HITS) model produces shipping density maps by estimating route envelopes from vessels' departure and destination points, using the shipping statistics released by major ports and commercial registers (Heitmeyer et al. 2003). Up to 10 ships per degree-square are seen at key locations, such as along the United States eastern seaboard. Less than 1 ship per degree-square is seen in most of the deep-water North Pacific and North Atlantic. When vessels cross continental slopes, downslope propagation of acoustic energy allows it to couple into the deep sound channel (Dosso \& Chapman 1987). This phenomenon is important to long-range deepocean propagation of ship-generated noise and ex- 


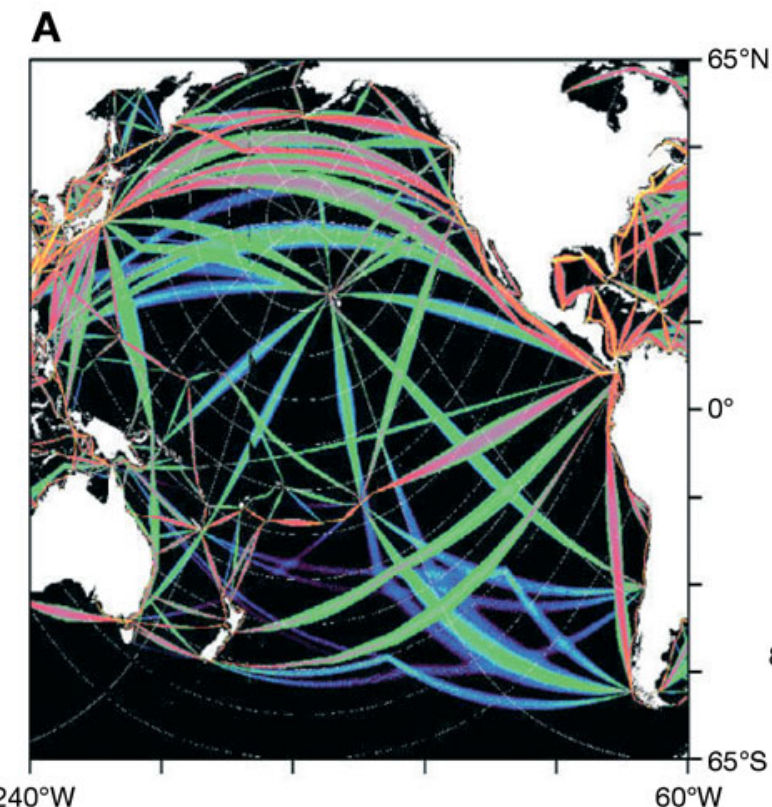

B
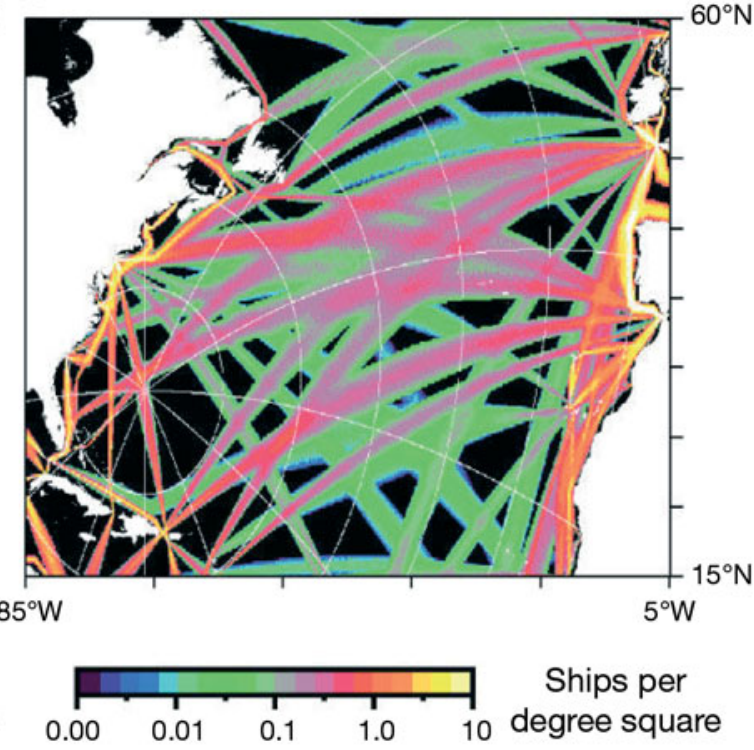

Fig. 2. Example of historical temporal shipping (HITS-IV) distribution, derived from a United States Naval Oceanographic Office shipping traffic database for (A) the Pacific Ocean and (B) the North Atlantic Ocean. Courtesy of Richard Heitmeyer (US Naval Research Laboratory)

plains some of the nature of low-frequency ambient noise, such as its horizontal directionality. At high latitudes, the deep-ocean sound channel intersects the ocean surface (Chow \& Turner 1982), and, in this region, shipping noise is readily coupled into the sound channel, allowing long-range propagation.

Ambient noise at low frequencies is generally related to regional shipping densities and propagation conditions. There is an asymmetry in shipping densities between the northern and southern hemispheres, with greater levels of ship traffic occurring in the north (Fig. 2). Greater northern shipping density explains why ambient noise at some sites in the southern hemisphere may be $20 \mathrm{~dB}$ less than the northern hemisphere average (Cato 1976). For instance, in the Timor Sea north of Australia, distant shipping noise is not a significant component of low-frequency ambient noise. High shipping densities in the Mediterranean result in high levels of ambient noise (Ross 2005).

\section{Shipping trends}

Over the past $50 \mathrm{yr}$ there has been a significant increase in the number and size of vessels comprising the world's merchant fleet (Fig. 3). Lloyd's Register indicates that the world's commercial fleet has approximately tripled during the past $50 \mathrm{yr}$, and during the same time period the gross tonnage of commercial vessels increased by a factor of $>6$. Although gross tonnage is an imperfect measure of vessel size, these data suggest that as the number of vessels grew, the size of individual vessels also substantially increased. Fig. 3 reveals that during the 1980s the world fleet gross tonnage remained nearly constant, and this was due primarily to a decrease in oil tanker capacity (UNCTAD 2005), which compensated for increases in dry bulk and container ship capacity. From the 1990s onward there has been a significant increase in the number and size of container ships, but the size increases are not well reflected in the gross tonnage values, since for these vessels a substantial portion of the cargo space is not included in the gross tonnage calculation. It is unclear, however, how vessel gross tonnage or size relates to radiated ambient noise (Heitmeyer et al.

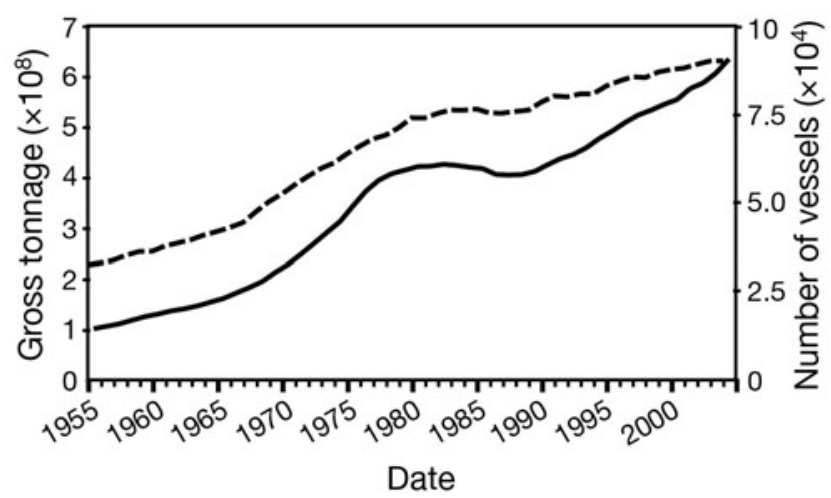

Fig. 3. Numbers of vessels (dashed line) and gross tonnage of vessels (continuous line) in the world's fleet. Data from Lloyd's register of shipping for self-propelled, merchant fleet vessels of 100 gross tons or above 
2003), and other vessel characteristics, such as total propulsion power, may be a better proxy for their noise emissions (Ross 1976).

It has been suggested that low-frequency ocean ambient noise spectrum levels increased by $10 \mathrm{~dB}$ or more between 1950 and 1975 (Ross 1976). These trends were most apparent in the eastern Pacific and North Atlantic, where they were attributed to increases in commercial shipping, both in the number of vessels and the noise radiated by the average vessel (Ross 2005). Other indications of long-term ambient noise trends (Fig. 4) come from comparison of historical United States Navy data from the 1960s (Wenz 1969), with modern recordings along the west coast of North America (Andrew et al. 2002, McDonald et al. 2006), suggesting an average increase of about $3 \mathrm{~dB}$ decade $^{-1}$. All these data taken together provide evidence for an overall increase of at least $20 \mathrm{~dB}$ in low-frequency ambient noise from preindustrial conditions to the present.

As shipping noise levels have increased, the boundary between wind-dominated and shipping-dominated noise has shifted to higher frequencies (Ross 1976). In settings with high concentrations of shipping, the frequency boundary between wind-dominated and shipping-dominated noise was suggested to be at $400 \mathrm{~Hz}$, even in the late 1950s (Walkinshaw 2005).

Since acoustic attenuation has a dependence upon seawater acidity, it has been suggested that increasing ocean acidification from rising $\mathrm{CO}_{2}$ levels will result in decreased sound absorption and, therefore, increased levels of ocean ambient noise (Hester et al. 2008). At frequencies $<100 \mathrm{~Hz}$, however, this effect may not be significant, since attenuation at low frequencies is negligible $\left(<10^{-3} \mathrm{~dB} \mathrm{~km}^{-1}\right)$. In the 200 to $500 \mathrm{~Hz}$ band, however, reduced attenuation could shift the crossover between shipping-dominated and wind-dominated ambient noise upward in frequency.

\section{Oil exploration noise and distribution}

Offshore exploration for oil and gas constitute another significant source of low-frequency ocean ambient noise. Offshore oil and gas exploration and construction activities occur along continental margins. Currently active areas include northern Alaska and northwestern Canada, eastern Canada, the United States and Mexican Gulf of Mexico, Venezuela, Brazil, southern Argentina, West Africa, South Africa, the North Sea, the Middle East, northwestern and southern Australia, New Zealand, southern China, Vietnam, Malaysia, Indonesia, and the Sea of Okhotsk (Fig. 5).

A database of industry seismic activities during the period from 1994 to 2005 was obtained from the World Geophysical News, an oil industry news agency, to

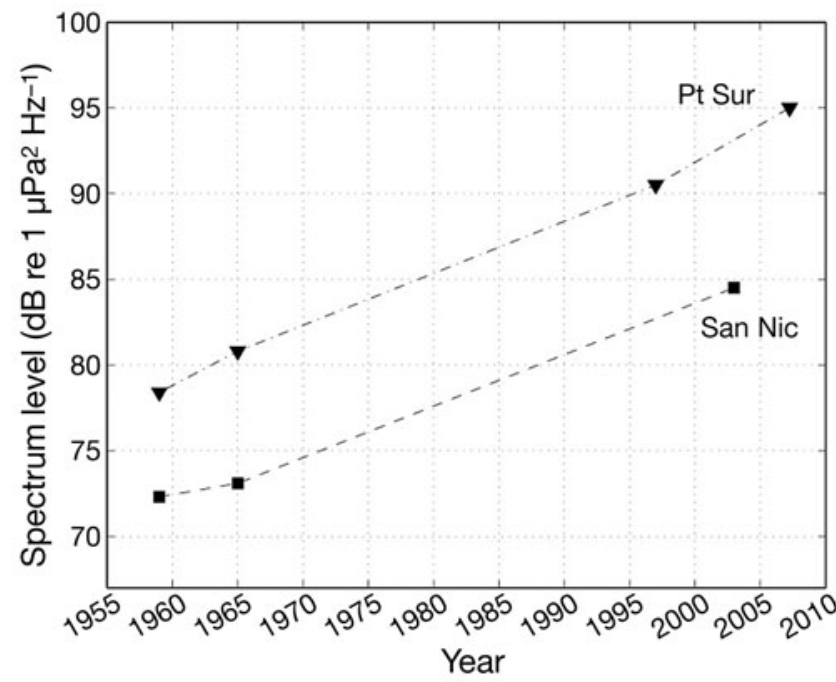

Fig. 4. Historical ambient noise data from the northeastern Pacific at $40 \mathrm{~Hz}$ suggest an increase of about $3 \mathrm{~dB}_{\text {decade }}^{-1}$, averaged over the past $40 \mathrm{yr}$, although details of how noise levels changed between measured times (points) are unknown. Data from the United States Navy hydrophone arrays near Pt Sur and San Nicolas Island (Wenz 1961, 1968, 1969) and from recent measurements at these sites (Andrew et al. 2002, McDonald et al. 2006, Cocker 2008)

outline patterns in the temporal and spatial use of offshore seismic surveys (Fig. 6). Over the past decade, the United States Gulf of Mexico had the highest level of activity, averaging about 25 offshore oil exploration crews in operation per month. Other areas of high activity include the North Sea, Nigeria, Brazil, Malaysia, Indonesia, India, the northwestern coast of Australia, and Sakhalin Island (Russia). Trends in the 1994 to 2005 time frame were for fewer seismic surveys (an average of 100 crews $\mathrm{mo}^{-1}$ operating in 1994 diminished to 40 crews $\mathrm{mo}^{-1}$ in 2004), although the most recent trend is for an increasing number of ships and surveys, owing to recent increases in oil prices.

Oil industry operations have traditionally been conducted in shallow water on the continental shelf, but, in recent years, the trend has been to conduct exploration in deeper waters $(>500 \mathrm{~m})$ along the continental slope. For instance, deep-water regions of the United States Gulf of Mexico and West Africa have seen increasing activity in the past 5 to $10 \mathrm{yr}$. In deep-water settings there is a greater potential for sound to propagate great distances, crossing ocean basins, by coupling into the deep sound channel. Due to oil exploration in deeper water and high levels of activity, seismic exploration is a significant contributor to ocean ambient noise in several ocean basins including the Gulf of Mexico, the North and South Atlantic, and the North Sea. A recent study of ambient noise in the North Atlantic found that seismic exploration along the continental margins of Canada, South America, and 


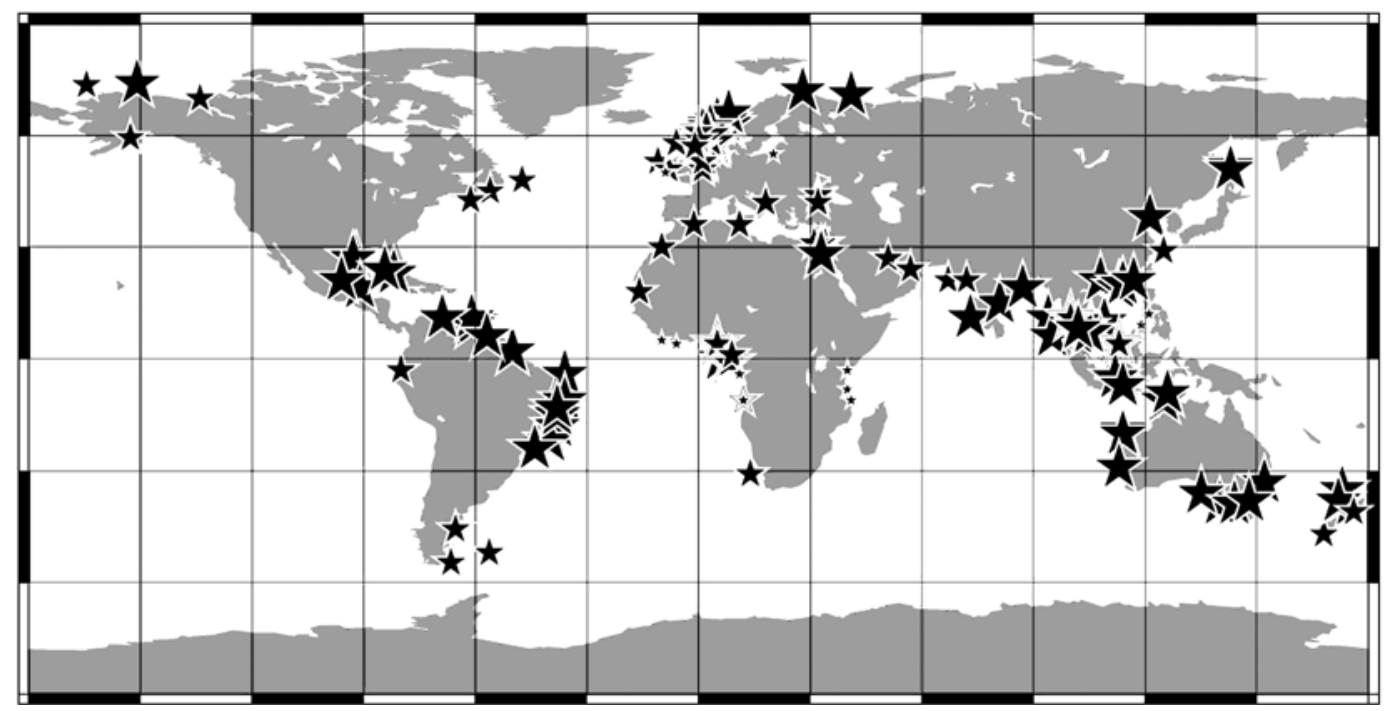

Fig. 5. Areas of offshore oil exploration from 1994 to 2005. Size of star denotes the relative level of activity. Data from the World Geophysical News

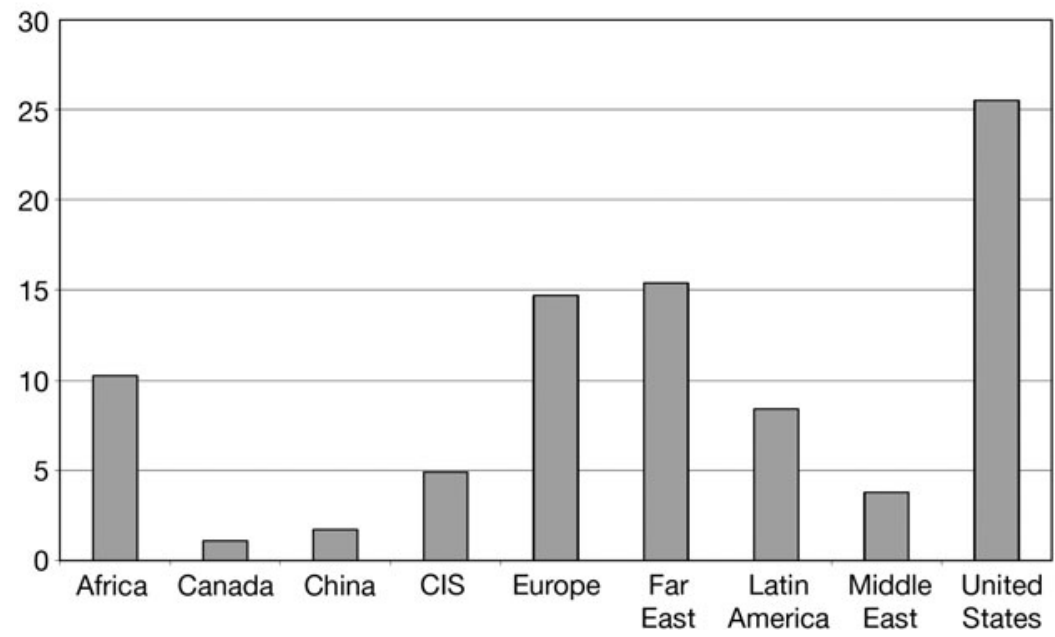

Fig. 6. Average numbers of offshore oil exploration crews working per month, given by region from 1994 to 2005. CIS: former states of the Soviet Union. See Fig. 5 for locations (Australia, New Zealand and SE Asia are included in 'Far East'). Data from the World Geophysical News
Myrberg \& Fuiman 2002). Fish sounds are produced in a variety of ways, most commonly by stridulation (e.g. grinding or strumming) or by using muscles on the swim bladder or connected to bones around the swim bladder. Sounds produced by stridulation are typically broadband pulses, whereas, sounds produced by sonic muscles on the swim bladder are pulsed tonals. Currently, most fish sounds are unknown due to a lack of detailed study. Fish not only produce sounds as individuals, but also in choruses (Cato \& McCauley 2002), which are highly variable by species, time of day, and season. The increase in low-frequency noise can be as much as from 20 to $30 \mathrm{~dB}$ in the presence of chorusing fishes.
West Africa propagates into the deep-ocean sound channel and is a significant component of low-frequency noise (Nieukirk et al. 2004). Air-gun sounds were recorded in the North Atlantic almost continuously during the summer months, originating at locations $>3000 \mathrm{~km}$ from the receiving hydrophones.

\section{Noise due to fishes}

Fish create low-frequency sounds (50 to $2000 \mathrm{~Hz}$, most often 100 to $500 \mathrm{~Hz}$ ) that can be a significant component of local ambient noise (Zelick \& Mann 1999,

\section{MID-FREQUENCY AMBIENT NOISE}

\section{Noise due to surface motion}

Noise from breaking waves is a major source of ocean ambient noise, dominating measured spectra between $500 \mathrm{~Hz}$ and $50 \mathrm{kHz}$. Ocean ambient noise due to sea-surface agitation was first systematically described by Knudsen et al. (1948), using measurements at mid-frequencies and in shallow water $(<200 \mathrm{~m})$. Ambient noise was found to increase with sea-surface motion, varying with local wind speed and sea state. The results of Knudsen et al. (1948) are codified as a 
series of curves, which predict ambient noise level for a range of sea states as follows:

$$
\begin{aligned}
\mathrm{NL} & =56+19 \log (\mathrm{ss})-17 \log f \\
& (\text { in } \mathrm{dB} \text { re } 1 \mu \mathrm{Pa} / \sqrt{\mathrm{Hz}})
\end{aligned}
$$

where ss is the sea state, for $1<\mathrm{ss}<6$; $f$ is frequency, for $1<f<25 \mathrm{kHz}$; and NL is the noise level in a $1 \mathrm{~Hz}$ band. The spectral shape of wind-generated noise has a slope of $17 \mathrm{~dB}$ decade $^{-1}$, decreasing by $29 \mathrm{~dB}$ from its peak near $500 \mathrm{~Hz}$ to $25 \mathrm{kHz}$. Ocean noise follows the spectral shape of the Knudsen curves only for frequencies $>1000 \mathrm{~Hz}$; below this the spectrum is relatively flat or decreasing (Cato 1976, Bannister et al. 1979, Wilson 1979, Burgess \& Kewley 1983, McDonald et al. 2008), until intersecting the zone of ambient noise dominated by shipping (Fig. 1).

The primary mechanisms of ocean-surface agitation are wind-generated breaking waves and the impact of raindrops (Franz 1959, Ma et al. 2005). Surface impacts have 2 distinct noise generation mechanisms, both of which radiate preferentially downward, with cosine directionality. A sharp pressure pulse is created by the impact of a water drop on the surface, followed by resonance pulsation of gas bubbles injected by the impact. The radiated spectrum of the impact covers a wide frequency band and varies with drop size and impact speed. Subsequent bubble pulsations produce spectra with sharp peaks, between $500 \mathrm{~Hz}$ and $10 \mathrm{kHz}$, with the size of the bubble determining its resonant frequency (Devin 1959). This model does a good job of explaining the general shape of ocean ambient noise data at mid-frequencies, including its peak in the 500 to $1000 \mathrm{~Hz}$ band, and the negative slope $(-17 \mathrm{~dB}$ decade $^{-1}$ ) for higher frequencies, described by the Kundsen curves. The model also helps to explain increases in ambient noise at mid-frequency, of as much as $20 \mathrm{~dB}$, due to heavy precipitation.

\section{Anthropogenic mid-frequency noise}

Sonar usage is a significant source of anthropogenic noise at mid-frequencies. Mid-frequency military sonars (e.g. SQS-53C; Table 1) have significant SPLs, acoustic power, and total ping energy. They are the most intense sources of mid-frequency noise, and are incorporated into the hulls of many naval surface vessels such as destroyers, cruisers, and frigates. There are 117 of these sonars on United States Navy ships in active service, and equivalent systems in foreign navies bring the worldwide count to about 300 (Watts 2003 ), which are thought to be operated about $10 \%$ of the time these vessels are at sea. Although these sonars are primarily operated in areas with on-going military conflicts and in areas of naval training, they have been implicated in marine mammal strandings and behavioral reactions to sound (Evans \& England 2001, NMFS 2005). Since attenuation limits the range of mid-frequency sound propagation, concern for the impact of these sonars is at local ranges. AHDs also have high source levels and acoustic power levels, and they are known to contribute locally to mid-frequency ambient noise. It has been suggested that AHDs can exclude marine mammals from areas of their usage (Morton \& Symonds 2002). Multibeam hull-mounted echosounders have high source levels, but the irregularity of their usage and their narrow ensonification beam widths may limit their contribution to overall ambient noise levels.

Small boats have moderate acoustic source levels at mid-frequencies. The large number of small vessels, which are owned and operated for a variety of purposes (e.g. fishing, recreation), suggests that they may elevate ambient noise levels, at least in a local setting. The mid-frequency noise of small boats does not propagate far $(\sim 10 \mathrm{~km})$ owing to acoustic attenuation, but the persistence of their sounds is aided by the lower levels of ambient noise at mid-frequencies. Small boat noise may be an important component of background noise in certain coastal regions. For instance, areas near urban populations with substantial recreational boating or areas with concentrated whale-watching activity may be especially prone to small boat noise (Veirs \& Veirs 2006). Over 17 million small boats are owned in the United States alone. Many of these boats use mid-frequency and high-frequency sonar for echolocation, also contributing to local ambient noise.

\section{Snapping shrimp noise}

At mid-frequencies, snapping shrimp Alpheus spp. and Synalpheus spp. can be the dominant source of mid-frequency ambient noise (Everest et al. 1948). These shrimp have an enlarged claw that produces a water jet with broadband acoustic energy. In a study at Kaneohe Bay, Hawaii, the peak-to-peak source levels of individual snaps from shrimp varied from 183 to 189 $\mathrm{dB}$ re $1 \mu \mathrm{Pa} @ 1 \mathrm{~m}$, with a typical peak spectrum between 2 and $5 \mathrm{kHz}$ and energy extending to $200 \mathrm{kHz}$ (Au \& Banks 1998). The presence of snapping shrimp can increase ambient noise levels by $20 \mathrm{~dB}$ in the midfrequency band.

\section{HIGH-FREQUENCY AMBIENT NOISE}

For sound receivers at depth, ambient noise spectral levels decrease much more rapidly with frequency than predicted by the Kundsen curves (see Fig. 1). This 
is because agitation noise due to wind and waves is confined to being at or near the sea surface and also due to significant attenuation of surface noise before it reaches receivers located at depth. Sound transmission is strongly dependent upon frequency, and, at high frequencies ( $>25 \mathrm{kHz}$ ), sound attenuation becomes an important factor in determining ocean ambient noise levels. Measurements of sound attenuation by seawater have revealed several absorption mechanisms including molecular viscosity, chemical relaxation, and oceanographic scattering (Fisher \& Simmons 1977). While the dependence of attenuation on frequency, pressure, temperature, salinity, and acidity is complex (Francois \& Garrison 1982a,b), the relation can be approximated as:

$$
\begin{aligned}
& \alpha=0.106 \frac{f_{1} f^{2}}{f^{2}+f_{1}^{2}} \mathrm{e}^{(\mathrm{pH}-8) / 0.56} \\
& +0.52\left(1+\frac{T}{43}\right)\left(\frac{S}{35}\right) \frac{f_{2} f^{2}}{f^{2}+f_{2}^{2}} \mathrm{e}^{-z / 6}+0.00049 f^{2} \mathrm{e}^{-(T / 27+z / 17)}
\end{aligned}
$$

where $f_{1}=0.78(S / 35)^{1 / 2} \mathrm{e}^{T / 26}$ and $f_{2}=42 \mathrm{e}^{T / 17}, \alpha$ is attenuation $\left(\mathrm{dB} \mathrm{km}^{-1}\right), f$ is frequency $(\mathrm{kHz}), \mathrm{pH}$ is acidity, $T$ is temperature $\left({ }^{\circ} \mathrm{C}\right), S$ is salinity $(\%)$, and $z$ is depth $(\mathrm{km})$ (Ainslie \& McColm 1998). Note that the attenuation coefficient $(\alpha)$ increases rapidly with frequency; for instance, at $10 \mathrm{kHz}$ the attenuation coefficient is $\sim 1 \mathrm{~dB} \mathrm{~km}^{-1}$, whereas at $100 \mathrm{kHz}$ the attenuation coefficient is $36 \mathrm{~dB} \mathrm{~km}^{-1}$. At frequencies below $\sim 1 \mathrm{kHz}$, the attenuation is dominated by a chemical relaxation of boric acid, which is dependant upon the $\mathrm{pH}$ of seawater. Increasing acidity (decreasing $\mathrm{pH}$ ) decreases low-frequency absorption, leading to lesser attenuation by about a factor of 2 in the North Pacific ( $\mathrm{pH}$ 7.7) relative to the Atlantic ( $\mathrm{pH} \mathrm{8)}$.

A model has been developed for the decay of ambient noise with depth, using an incoherent sum of all the surface noise sources (Short 2005, Kurahashi \& Gratta 2008). At $60 \mathrm{kHz}$, the attenuation of surface noise is about $20 \mathrm{~dB}$ per $1000 \mathrm{~m}$ depth, so thermal noise becomes the dominant noise source at $1000 \mathrm{~m}$ depth, even in the presence of high sea states (Fig. 1). The result is extremely low ambient noise levels at high frequencies when deeply submerged. Receiver depth is, therefore, a key parameter setting ambient noise levels. Note that the occurrence of low noise levels at depth will be important to deep-diving marine mammals, such as beaked whales, since the ambient noise they experience as a background for echolocation will decrease rapidly with depth.

\section{Thermal noise}

Thermal agitation of molecules in seawater creates noise that limits acoustic detection sensitivity at high frequencies $(>50 \mathrm{kHz})$. When all external noise sources are removed, a minimum noise level, determined by the thermal excitation of the medium itself, sets an absolute upper limit on the sensitivity of the acoustic detection system (this is true for both hydrophone and animal hearing systems).

Mellen (1952) developed a theoretical model for thermal noise based on classical statistical mechanics, reasoning that the average energy per degree of freedom is $k T$ (where $k$ is Boltzmann's constant and $T$ is absolute temperature). The number of degrees of freedom is equal to the number of compressional modes, yielding an expression for the plane-wave pressure owing to thermal noise in water. For non-directional hydrophones and typical ocean temperatures, the background level due to thermal noise is given by:

$$
\mathrm{NL}=-15+20 \log f \quad(\text { in } \mathrm{dB} \text { re } 1 \mu \mathrm{Pa})
$$

where $f$ is given in $\mathrm{kHz}$ with $f \gg 1$, and NL is the noise level in a $1 \mathrm{~Hz}$ band. Note that thermal noise increases at the rate of $20 \mathrm{~dB}$ decade ${ }^{-1}$. There are few measurements in the high-frequency band to suggest deviations from the predicted levels.

\section{Anthropogenic high-frequency noise}

Sonars used for shallow-water echosounding (Table 1) and for locating small objects, such as fish, require high frequencies to provide sufficiently detailed resolution at relatively short distances. These high frequencies attenuate rapidly and, therefore, have only local effects. However, stationary sound sources, such as modems used for acoustic telemetry, could lead to local ambient noise increases in the high-frequency range.

\section{AMBIENT NOISE RESEARCH NEEDS}

Understanding of ocean ambient noise is incomplete, despite substantial investment in the collection of underwater sound data for research, commercial, and military purposes. Expanding use of the sea for shipping, oil and gas development, and undersea warfare has resulted in ambient noise levels that are higher today than they were a few decades ago. Mid- and high-frequency anthropogenic noise has expanded owing to greater use of sonar and increased small boat traffic. Without some effort to monitor, reduce, or at least cap these noise levels, they are likely to continue to increase.

An important component of ambient noise modeling is better understanding of the signal characteristics for representative anthropogenic sound sources. For 
instance, more information is needed on surface ship noise spectra. These noise source descriptions should include frequency content, pressure time series, duration, repetition rate, directionality, and other key parameters. Given that vessel traffic is ubiquitous in many coastal areas and other areas with marine mammal habitat, more measurements are needed of vessel noise within the frequency range of marine mammal echolocation (1 to $100 \mathrm{kHz}$ ). These studies should investigate the effects of vessel size, propulsion type, operating speed, and other operating parameters on noise levels. Research should be conducted on how the level of anthropogenic activity (such as the types and numbers of vessels) is related to resulting noise levels. These relations will help to extend noise modeling to areas without direct long-term monitoring, but where anthropogenic noise sources are present.

Better data are needed on the locations of noise sources, and environmental data are needed to model sound propagation. For instance, surface ship geographic distributions and tracklines for seismic profiling are needed. At locations with concentrations of sources, bathymetry, sound-speed profiles, local winds, and wind-wave noise spectra are needed to allow better modeling of the relative contribution of anthropogenic noise and natural noise sources. Marine noise measurements and source data could be used to develop a global model of ocean noise. The development of an accurate global model depends on access to ocean noise data and anthropogenic activity data. A basic tenant of noise modeling is that observed noise levels will increase with increased density of noise sources.

A long-term monitoring program is needed to track future changes in ocean noise. Acoustic data should be included in global ocean observing systems now being developed. Data from these monitoring systems should be openly available and presented in a manner accessible to decision makers in industry, the military, and regulatory agencies.

Acknowledgements. I thank Don Ross for patient tutoring on ambient noise. Mark McDonald, Sean Wiggins, Christian DeMoustier, Doug Nowacek and 2 anonymous reviewers provided helpful comments. Financial support was given by Frank Stone and Ernie Young of the US Navy Chief of Naval Operations N45, Curt Collins of the Naval Postgraduate School, and Brandon Southall of the NOAA Office of Protected Resources, Acoustics Program. Michael Jasney provided access to the World Geophysical News database, and Richard Heitmeyer provided output from the HITS shipping model.

\section{LITERATURE CITED}

Ainslie M, McColm J (1998) A simplified formula for viscous and chemical absorption in sea water. J Acoust Soc Am 103:1671-1672
Andrew RK, Howe BM, Mercer JA, Dzieciuch MA (2002) Ocean ambient sound: comparing the 1960s with the 1990s for a receiver off the California coast. Acoust Res Lett Online 3:65-70

Anonymous (2007) Final supplemental environmental impact statement for surveillance towed array sensor system low frequency active (SURTASS LFA) sonar, Vols 1 and 2. Department of the Navy, Chief of Naval Operations, Arlington, VA

Au WWL (1993) The sonar of dolphins. Springer-Verlag, New York

Au WWL, Banks K (1998) The acoustics of the snapping shrimp Synalpheus parneomeris in Kaneohe Bay. J Acoust Soc Am 103:41-47

Awbrey F, Thomas JA (1987) Measurements of sound propagation from several acoustic harassment devices. In: Mate BR, Harvey JT (eds) Acoustical deterrents in marine mammal conflicts with fisheries. Oregon State University, Corvallis, p 85-104

Bannister RW, Denham RN, Guthrie KM, Browning DG, Perrone AJ (1979) Variability of low-frequency ambient sea noise. J Acoust Soc Am 65:1156-1163

Bass AH, McKibben JR (2003) Neural mechanisms and behaviors for acoustic communication in teleost fish. Prog Neurobiol 69:1-26

Blackwell SB, Greene CR Jr, Richardson WJ (2004) Drilling and operational sounds from an oil production island in the ice-covered Beaufort Sea. J Acoust Soc Am 116:3199-3211

Burgess AS, Kewley DJ (1983) Wind-generated surface noise source levels in deep water east of Australia. J Acoust Soc Am 73:201-210

Butler R (2006) Observations of polarized seismoacoustic T waves at and beneath the seafloor in the abyssal Pacific Ocean. J Acoust Soc Am 120:3599-3606

Caltrans (California Department of Transportation) (2001) Pile installation demonstration project, fisheries impact assessment. Caltrans Contract 04A0148, Oakland Bay Bridge East Span Seismic Safety Project, San Francisco

> Cato DH (1976) Ambient sea noise in waters near Australia. J Acoust Soc Am 60:320-328

Cato DH, McCauley RD (2002) Australian research in ambient sea noise. Acoust Aust 30:13-20

Chow RK, Turner RG (1982) Attenuation of low-frequency sound in the Northeast Pacific Ocean. J Acoust Soc Am 72: 888-891

Christian EA, Gaspin JB (1974) Swimmer safe standards from underwater explosions. Navy Science Assistance Program Project No. PHP-11-73, Naval Ordnance Laboratory, White Oak, MD

Cocker P (2008) Observations of ocean ambient noise $(10 \mathrm{~Hz}$ to $10 \mathrm{kHz}$ ) at the site of a former navy listening station to the west of Point Sur, California, from January to July of 2007. Masters of Science, Naval Postgraduate School, Monterey, CA

- Devin C (1959) Survey of thermal, radiation, and viscous damping of pulsating air bubbles in water. J Acoust Soc Am 31: 1654-1667

DoN (Department of the Navy) (2009) Notice of intent to prepare a Supplemental Environmental Impact Statement/ Supplemental Overseas Environmental Impact Statement for employment of surveillance Towed Array Sensor System Low Frequency Acrive (SURTASS LFA) sonar. Federal Register 74(12):3574-3575 (microfiche)

$>$ Dosso SE, Chapman NR (1987) Measurement and modeling of downslope acoustic propagation loss over a continental slope. J Acoust Soc Am 81:258-268

Dragoset W (1984) A comprehensive method for evaluating 
the design of air guns and air gun arrays. Geophys Lead Edge Explor 3:52-61

$>$ Dragoset W (2000) Introduction to air guns and air-gun arrays. Geophys Lead Edge Explor 19:892-897

Edds-Walton PL (1997) Acoustic communication signals of mysticete whales. Bioacoustics 8:47-60

Erbe C (2002) Underwater noise of whale-watching boats and potential effects on killer whales (Orcinus orca), based on an acoustic impact model. Mar Mamm Sci 18:394-418

Evans DL, England GR (2001) Joint interim report Bahamas marine mammal stranding event of 14-16 March 2000. US Department of Commerce and US Navy. Available at: www.nmfs.noaa.gov/prof_res/overview/Interim_Bahamas Report.pdf

Everest FA, Young RW, Johnson MW (1948) Acoustical characteristics of noise produced by snapping shrimp. J Acoust Soc Am 20:137-142

Fisher FH, Simmons VP (1977) Sound absorption in sea water. J Acoust Soc Am 62:558-564

Francois RE, Garrison GR (1982a) Sound-absorption based on ocean measurements. 1. Pure water and magnesium-sulfate contributions. J Acoust Soc Am 72:896-907

> Francois RE, Garrison GR (1982b) Sound-absorption based on ocean measurements. 2. Boric-acid contribution and equation for total absorption. J Acoust Soc Am 72:1879-1890

Franz GJ (1959) Splashes as sources of sound in liquids. J Acoust Soc Am 31:1080-1096

Greene CR Jr (1987) Characteristics of oil industry dredge and drilling sounds in the Beaufort Sea. J Acoust Soc Am 82:1315-1324

Halpern BS, Walbridge S, Selkoe KA, Kappel CV and others (2008) A Global map of human impact on marine ecosystems. Science 319:948-952

Heitmeyer RM, Wales SC, Pflug LA (2003) Shipping noise predictions: capabilities and limitations. Mar Technol Soc J 37: $54-65$

Hester KC, Peltzer ET, Kirkwood WJ, Brewer PG (2008) Unanticipated consequences of ocean acidification: a noisier ocean at lower pH. Geophys Res Lett 35:L19601

Hildebrand JA (2005) Impacts of anthropogenic sound. In: Reynolds JE, Perrin WF, Reeves RR, Montgomery S, Ragen TJ (eds) Marine mammal research: conservation beyond crisis. The Johns Hopkins University Press, Baltimore, MD, p 101-124

Johnson J (2002) Final overseas environmental impact statement and environmental impact statement for surveillance towed array sensor system low frequency active (SURTASS LFA) sonar, Vols 1 and 2. Department of the Navy, Chief of Naval Operations, Arlington, VA

Kewley DJ, Browning DG, Carey WM (1990) Low-frequency wind-generated ambient noise source levels. J Acoust Soc Am 88:1894-1902

Kipple B, Gabriele C (2003) Glacier Bay watercraft noise. Technical Report NSWCCDE-71-TR-2003/522, prepared for Glacier Bay National Park and Preserve, Naval Surface Warfare Center, Bremerton, WA

Kipple B, Gabriele C (2004) Glacier Bay watercraft noisenoise characterization for tour, charter, private, and government vessels. Technical Report NSWCCDE-71-TR2004/545, prepared for Glacier Bay National Park and Preserve, Naval Surface Warfare Center, Bremerton, WA

Kipple B, Kollars R (2004) Coral Princess underwater acoustic levels. Technical Report, Naval Surface Warfare Center, Detachment Bremerton

Knudsen VO, Alford RS, Emling JW (1948) Underwater ambient noise. J Mar Res 7:410-429

Kuperman WA (1988) Propagation effects associated with ambient noise. In: Kerman BR (ed) Sea surface sound: natural mechanisms of surface generated noise in the ocean. Kluwer, Dordrecht, p 253-272

Kurahashi N, Gratta G (2008) Ocean ambient noise as a background to acoustic neutrino detection. Phys Rev D 78: 092001(2008)

Ma BB, Nystuen JA, Lien RC (2005) Prediction of underwater sound levels from rain and wind. J Acoust Soc Am 117: 3555-3565

Madsen PT (2005) Marine mammals and noise: problems with root mean square sound pressure levels for transients. J Acoust Soc Am 117:3952-3957

Madsen PT, Johnson M, Miller PJ, Aguilar Soto N, Lynch J, Tyack P (2006) Quantitative measures of air-gun pulses recorded on sperm whales (Physeter macrocephalus) using acoustic tags during controlled exposure experiments. J Acoust Soc Am 120:2366-2379

McDonald MA, Hildebrand JA, Wiggins SM (2006) Increases in deep ocean ambient noise in the Northeast Pacific west of San Nicolas Island, California. J Acoust Soc Am 120: 711-718

> McDonald MA, Hildebrand JA, Wiggins SM, Ross D (2008) A fifty year comparison of ambient ocean noise near San Clemente Island: a bathymetrically complex coastal region off southern California. J Acoust Soc Am 124:1985-1992

Mellen R (1952) The thermal-noise limit in the detection of underwater acoustic signals. J Acoust Soc Am 24:478-480

Morton AB, Symonds HK (2002) Displacement of Orcinus orca (L.) by high amplitude sound in British Columbia, Canada. ICES J Mar Sci 59:71-80

Munk WH, O'Reilly WC, Reid JL (1988) Australia-Bermuda Sound Transmission Experiment (1960) revisited. J Phys Oceanogr 18:1876-1898

Myrberg AA, Fuiman LA (2002) The sensory world of coral reef fishes. In: Sale PF (ed) Coral reef fishes: dynamics and diversity in a complex system. Academic Press, San Diego, CA, p 123-148

Myrick AC, Fink M, Glick CB (1990) Identification, chemistry, and behavior of seal bombs used to control dolphins in the yellowfin tuna purse seine fishery in the eastern tropical Pacific: potential hazards. SWFC Administrative Report, SWFSC, La Jolla, CA

Nieukirk SL, Stafford KM, Mellinger DK, Dziak RP, Fox CG (2004) Low-frequency whale and seismic airgun sounds recorded in the mid-Atlantic Ocean. J Acoust Soc Am 115: 1832-1843

NMFS (National Marine Fisheries Service) (2001) Record of decision for the final environmental impact statement for shock trial of WINSTON S. CHURCHILL (DDG 81). Federal Register 66(87):22536-22538 (microfiche)

NMFS (2005) Assessment of acoustic exposures on marine mammals in conjunction with USS Shoup active sonar transmissions in the eastern Strait of Juan de Fuca and Haro Strait, Washington. NMFS, Office of Protected Resources. Available at: www.nmfs.noaa.gov/pr/pdfs/ acoustics/assessment.pdf

NRC (National Research Council) (2003) Ocean noise and marine mammals. NRC, Washington DC

Pepper PA, Turner VLG, Goodson AD, Black KD (2004) Source levels and spectra emitted by three commercial aquaculture anti-predation devices. In: Simons DG, Blacquiere G (eds) Proc 7th European Conf on Underwater Acoustics, ECUA 2004. Commission of the European Communities, Delft

Richardson WJ, Greene CRJ, Malme CI, Thomson DH (1995) Marine mammals and noise. Academic Press, San Diego, CA 
Ross D (1976) Mechanics of underwater noise. Pergamon Press, New York

Ross D (2005) Ship sources of ambient noise. IEEE J Oceanic Eng 30:257-261

Schmidt V (2004) Seismic contractors realign equipment for industry's needs. Offshore 64:36-44

Short JR (2005) High-frequency ambient noise and its impact on underwater tracking ranges. IEEE J Oceanic Eng 30: $267-274$

Simmonds EJ, MacLennan DN (2005) Fisheries acoustics: theory and practice. Blackwell Publishing, London

Simpson SD, Meekan M, Montgomery J, McCauley R, Jeffs A (2005) Homeward sound. Science 308:221

Spiess FN, Northrup J, Werner EW (1968) Locations and enumeration of underwater explosions in the North Pacific. J Acoust Soc Am 43:640-641

Tolstoy M, Diebold JB, Webb SC, Bohnenstiehl DR, Chapp E, Holmes RC, Rawson M (2004) Broadband calibration of R/V Ewing seismic sources. Geophys Res Lett 31:L14310

Turner S, Zykov M, MacGillivray A (2006) Preliminary acoustic level measurements of airgun sources from Conoco Phillips' 2006 seismic survey in Alaskan Chukchi Sea. JASCO Research, Victoria, BC

UNCTAD (United Nations Conference on Trade and Development) (2005) Review of maritime transport. United Nations, Geneva

Urick RJ (1975) Principles of underwater sound. McGrawHill, New York

Veirs S, Veirs V (2006) Vessel noise measurements underwater in the Haro Strait, WA. J Acoust Soc Am 120:3382

Wahlberg M, Westerberg H (2005) Hearing in fish and their reactions to sounds from offshore wind farms. Mar Ecol

Submitted: May 23, 2008; Accepted: October 2, 2009
Prog Ser 288:295-309

- Walkinshaw HM (2005) Measurements of ambient noise spectra in the South Norwegian Sea. IEEE J Oceanic Eng 30:262-266

Wartzok D, Ketten DR (1999) Marine mammal sensory systems. In: Reynolds JEI, Rommel S (eds) Biology of marine mammals. Smithsonian Institution Press, Washington DC, p 117-175

Watts AJ (2003) Jane's underwater warfare systems, 15th edn. IHS Jane's, Berkshire, UK

- Webb SC (1998) Broadband seismology and noise under the ocean. Rev Geophys 36:105-142

Wenz GM (1961) Periodic variations in low-frequency underwater ambient noise levels. Report 1014, Navy Electronic Laboratory, San Diego, CA

> Wenz GM (1962) Acoustic ambient noise in the ocean: spectra and sources. J Acoust Soc Am 34:1936-1956

Wenz GM (1968) Properties of deep-water, low-frequency, ambient noise west of San Diego, California. TP 39, Naval Undersea Warfare Center, San Diego, CA

Wenz GM (1969) Low-frequency deep-water ambient noise along the Pacific Coast of the United States. US Navy J Underw Acoust 19:423-444

Wenz GM (1972) Review of underwater acoustics research: noise. J Acoust Soc Am 51:1010-1024

Wilson JH (1979) Very low frequency (VLF) wind-generated noise produced by turbulent pressure fluctuations in the atmosphere near the ocean surface. J Acoust Soc Am 66:1499-1507

Zelick R, Mann DA (1999) Acoustic communication in fishes and frogs. In: Fay RR, Popper AN (eds) Comparative hearing: fishes and amphibians. Springer-Verlag, New York, p 363-412

Proofs received from author(s): November 13, 2009 